\author{
John M. Swales*, Henriette Jakobsen, Christina \\ Kejser, Lena Koch, Joan Lynch \& Lone Mфlbak ${ }^{1}$
}

\title{
A New Link in a Chain of Genres?
}

\begin{abstract}
Institutional genres often form dynamic systems or chains. In this paper we report on a possible expansion of the genre system that undergirds the appointment process of assistant professors in the U.S. This expansion consists of a "response letter" to a letter of recommendation. We first analyse a small corpus of these response letters by looking at the openings and closings and the bodies of the letters. The larger aim of this analysis is to explore the possible rationales that might underlie the composition, stylistic character and content of these texts.
\end{abstract}

\section{Introduction}

Following pioneering work by Devitt (1991) on tax correspondence and by Bazerman (1994) on patent application processes, there is a growing understanding that individual genres often form part of generic systems. These systems are often ordered in such a way that Text A leads to Text $\mathrm{B}$, which in turn engenders Text $\mathrm{C}$. In the academic world one well-known system of this sort is the chain of genres that orchestrate the process from submission to (hopefully) publication of an article; in the business world there is a comparable chain of documents, leading up to an official contract; and in both worlds recruitment for more important employment positions is increasingly governed by textually-mediated and highly-structured sequences of events. Indeed, in modern societies these generic systems continue to evolve both as a result of the decline of "old boy networks" and in consequence of the proliferation of

* John M. Swales

University of Michigan

English Language Institute

Ann Arbor M1 48109-1057 USA

1 Henriette Jakobsen, Christina Kejser, Lena Koch, Joan Lynch, Lone Mфlbak

Handelshøjskolen i Århus

Fuglesangs Allé 4

DK-8210 Arhus V 


\section{4}

administrative regulations. For example, several additional steps in the hiring process in the United States have been added as a result of Affirmative Action legislation, such as the papers of all chosen applicants have to be circulated through a special office to ensure that minority candidates have not been discriminated against.

The typical American "search" process for professorial positions involves the posting of the position, receiving applications, taking up references, making a short-list, conducting telephone or conference interviews, inviting two or three favored applicants for a campus visit, making an offer and so on. Usually, applicants invite three to five professors to write references, which are then sent to all the institutions which have asked for them. Since applicants for beginning assistant professor positions will likely apply for many jobs, the administrative load - beyond that of actually composing the letter - can be quite substantial, and often therefore departmental secretaries assist in the processes of changing the addressee details, printing on headed departmental notepaper, and mailing. Such recommendation letters or references are these days almost entirely laudatory of the candidate, partly because of the competitiveness of the job market and perhaps partly because of concern about potential litigation if negative comments are made. In such circumstances, reference letters, in order to stand out from their competitors, have tended to become longer and today typically run to 2-3 pages (Swales \& Feak, 2000).

It is common for such letters to end with some formulaic offer like "If you require any further information I can be most easily contacted at...". However, anecdotal evidence suggests that such offers are rarely taken up. At this point, many will likely presume that the reference letter sub-system has come to a close. The reference letter is read, acted on (or not) and then filed by the receiving party. As viewed from the perspective of the recommender, this is the end of this particular generic chain. However, in this short paper, we now present some preliminary evidence to suggest that, at least in certain circumstances, a letter of reference may generate an official note of acknowledgement and thanks. We here analyse a small corpus of such "response letters" and begin to explore the possible rationales that might underlie their composition, stylistic character and content. 


\section{The Corpus}

In September 1999, a professor of applied linguistics at a U.S. research university was asked by an international doctoral student in organizational psychology to write a reference letter for him. The student said that he would need about 50 letters as he was applying to 50 U.S. and Canadian Business Schools for an assistant professor position. The student and the professor's secretary offered to deal with the administrative details. A letter was duly written and 50 versions mailed out toward the end of the month. However, to the professor's total surprise, over the next week or so he received a number of "response letters", eventually totalling 14 , as well as half-a-dozen e-mail messages to the same effect which, unfortunately, he did not keep (overall a $40 \%$ reply rate). These 14 letters thus constitute the corpus for this small-scale study. As might be expected, the letters are short, averaging about 3.5 sentences each, the longest consisting of eight sentences and the two shortest of two sentences each. Here is a typical example (pseudonyms have been used):

Dear Dr. Moore

Thank you very much for your letter of recommendation for Ron Chung for a position on our faculty. Recommendations are an important part of our recruiting process and we appreciate the time and effort you put into providing thoughtful information. We will be getting back in touch with Mr. Ron Chung as our recruitment process unfolds.

Thanks again for your efforts on $M r X X X X$ 's behalf and our recruiting process.

Sincerely yours

(signature)

(name/title/position)

\section{Textual analysis}

We first deal with the opening and closing salutations, and the titles and terms of address associated with each, and then with the "body" of the response messages. 


\subsection{Openings and closings}

Although the actual reference letter had been closed by the professor's first name, middle initial and last name, all the response-letters were strictly formal. The breakdown is shown in Table 1.

\section{Table 1 Opening Terms of Address}

Form of saluation

Dear Professor Moore

Dear Dr. Moore

Dear Prof. Moore

Dear Mr. Moore
Number of Tokens

7

5

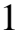

1

The only oddity here is the single instance of "Dear Prof. Moore", which seems to offer a combination of the informal "prof." with the formal "Moore" of a type perhaps more typical of academic speech. At first sight, it might be speculated that this letter had been written by a member of the clerical staff, but it is in fact signed by a professor and departmental chair.

The closings have been examined in terms of both the salutation used and the title below the signature. As might be expected from a corpus emanating from North American business schools, the standard salutation was the simple "sincerely". In addition, there were single occurrences of "sincerely yours", "respectfully" and "with best regards", the last two of which veer toward the very formal and the more informal, respectively. When we turn to the positions of those who wrote (or at least signed) the response-letters we come to perhaps our first surprise in the corpus. Thirteen of the 14 letters had status information following the signature, and in all these cases the positions indicated were academic-administrative rather than clerical. All were professors of some sort; additionally there was a dean, a sprinkling of departmental chairs or area coordinators and five chairs of the search/recruitment committee. We might suppose that since the reference letter was written by a professor to another professor, then there might be a presumption that he or she should be replied to in kind. Additionally, the letters may be being used to demonstrate to Dr Moore that these particular business schools take the appointment process very seriously, even to the extent of writing individual "response letters". The soi-disant care and attention devoted to the process might in turn be seen as sending positive 
signals about the working environment in the business school as a whole.

\subsection{The body of the letters}

As we have said, the letters are quite short; they are also quite similar rhetorically since most contain the same kind of themes: Thanking; appreciation of the time and effort taken; information on the recruitment process; and an indication of follow-up with the applicant. In fact, eleven of the 14 letters open with "Thank you for ...", to simply announce that they have received the letter, while the final one opens "We very much appreciate receiving your letter of reference..". Overall, "we" is very much the pronoun of choice, there being 31 instances of "we" and only three of "I". The plural form is clearly associated with the fact that the signer is writing on behalf of the search committee. The three instances of "I" all come from one author, a chair of a management department, as in "I have received your letter of recommendation supporting Ron Chung as a candidate for our position in the Management Department at...". Although there must be some doubt as to whether the signers actually wrote the letters using "we", in this case it is highly probable that the signer wrote the letter.

Perhaps the most interesting "move" (Bhatia, 1993) in this small corpus consists of statements about the onerous nature of recommendation letter writing. There were six of these (a $43 \%$ inclusion rate):

1. ....and we appreciate the time and effort you put into providing thoughtful information.

2. We realise the time and effort involved in preparing letters of recommendation for your colleagues or students, and we appreciate your willingness to offer us your insights about their qualifications.

3. Writing such letters is time consuming, but you can be sure that your efforts are of much help to us as....

4. We know the amount of time writing such letters can take and thoroughly appreciate your willingness to help in the search process.

5. I know how time consuming it is to write such letters, and I very much appreciate your candid and thoughtful evaluation. 
6. We appreciate your time and effort in writing this letter, and will be using it to aid our decision.

As the reader can see, there has been a determined effort in these six cases to communicate appreciation for the considerable work involved, as well as to reassure the recommender that his two-page letter has not been in vain. In the above examples this latter move is perhaps clearest in \#6 ("and will be using it to aid our decision."), but these statements occur elsewhere in several other texts. Two further typical examples are: "The search committee will give close attention to your letter" and "Your comments will play an important role in our efforts to find the most suitable candidate for this position".

Six of the letters also give some information as to what might be happening next, as in "We will be getting back in touch with Mr Chung as our recruiting process unfolds". This, we presume, can also be taken as a further signal that the recommendation letter has not been in vain, although we also note that the writers of response letters are careful not to leak any real information as to whether the applicant might or might not be short-listed and so on. Most of the letters end (apart from the closing salutation) by going back to where they begun - by thanking the writer for his contribution/assistance/efforts/input etc. However, one letter pre-closes with "Thank you for your interest in the University of X". This is decidedly odd in that there could have been little real expectation that Dr Moore would have had a particular interest in this particular institution. We suggest that this phrase has probably been borrowed, and not very successfully, from letters responding to casual employment or student applications.

\section{Searching for a rationale}

The small epistolary phenomenon that we have discussed in this paper indicates that the network of communications surrounding the U.S academic job application process may be expanding in one direction that of a short letter in response to receipt of a recommendation or reference letter. This phenomenon has not been attested in liberal arts colleges, or schools of education, but only in business schools, and even there a response rate of around $40 \%$ suggests that any new generic link is not yet firmly established. 
On the simplest level, we might conclude that these response letters are just simple notes thanking recommendation writers for their time and effort. But then the question arises as to why the response letter writers should go to this trouble when there is no general expectation in the academy that they need to do so. Given this, one further possibility is that of reciprocity of correspondence functioning as a kind of administrative politesse. Since the recommendation writer (or rather his secretary) took the time to personally address (and re-address) each of the fifty letters, then an equally personalized note of response might be anticipated.

Other explanations are possible. One such would include a wish to recognize and valorize this "free service", perhaps especially as some institutions now seem willing to pay for tenure and promotion evaluations. Another might be to ensure a continuing supply of "good quality" recommendation letters, and indeed the inclusion of the onerous move (as discussed in section 3.2 ) might provide some textual evidence for this kind of interpretation. A third would recognize that business school departments are probably the only academic units familiar with the substantial literature on customer care (e.g. Martin, 1998), and so have themselves implemented the advice given in this literature, such as "A quick courteous response letter saves time, creates goodwill and is a thousand times more profitable than any delay" (Freemantle, 1992:13). Additionally, the fact that the recommender was neither a professor of management nor of psychology, the applicant's two areas of expertise, might have played some role in generating letters to an "outsider".

A further possible motive might be to use the response letter as a way of indirectly promoting the particular institution in the eyes (and memory?) of the recommender. After all, all the responses were printed on (for the most part) rather fancy stationery and all were signed by fellow academics. However, if this is so, we should also point out that only one letter, in fact the longest, actually goes out of its way to promote the virtues of its school; here is one extract - "our somewhat unusual targeted blend of practically oriented research and strong dedication to quality education..". Finally, there is always the null hypothesis as it were; that perhaps after all there is no real or compelling rationale for these epistolary responses beyond the fact that, say, 20 years ago some head of department started this system and nobody since has bothered to stop it. But against such a null hypothesis there remains the incontro- 
vertible fact that responses were received from 20 different institutions and from all corners of North America. In other words, something seems to be going on, but what its more precise nature might be is unclear. As Swales notes "We need more socio-cognitive input than the text itself provides" (1993:690).

\section{A theoretical coda}

The relationship between genre and purpose, exigence and role has long been thought to be important, particularly in English for Specific Purposes, and continues to occupy a significant place in "new" North American genre theory and among systemic linguists (Hyon 1996). Several scholars (Swales, 1990, Bhatia, 1993, Johns 1997) have advocated using "sets of communicative purposes" as a primary means of typifying genre exemplars and thus assigning them to a particular genre membership category. However, as we have hoped to show, our small corpus consists of an obvious group of look-alike short and "simple" texts which we have analysed and to which we have affixed the label of response letter. Clearly the purpose of the text is to offer thanks in some general kind of way, but we do not know what motivates their production. While they are all engendered by the receipt of an earlier - and basically identical - piece of correspondence in the chain, we do not know from the textual forms themselves what their more specific communicative purposes are (see also Askehave, 1999), or indeed whether the formal similarities among them might presuppose some shared set of purposes, or might, alternatively, disguise different ones. Doubtless, much might be gained by contacting US business schools about their practices in regard to recommendation letters received, but this would be a rather long and laborious process, the outcomes of which would likely remain uncertain. In the end, the analyst may have to decide, once all the various kinds of evidence are in, what the best characterization of communicative purpose might be. Given all these perplexities, assigning communicative purpose is neither rapid nor transparent. For the discourse analyst, communicative purpose, even in "homely" genres such as this one (Miller, 1984), turns out to be a long-term and elusive goal, not a short-term sorting method. 


\section{Acknowledgements}

We would like to thank Philip Shaw for helpful comments on an earlier draft of this paper. Any remaining weaknesses are of course our own.

\section{References}

Askehave, Inger (1999). Communicative purpose as genre determinant. Hermes 23. 1323.

Bazerman, Charles (1994). Constructing experience. Carbondale, IL: Southern Illinois University Press.

Bhatia, Vijay K. (1993). Analysing genre. London: Longman.

Devitt, Amy (1991). Intertextuality in tax accounting: Generic, referential and functional. In Bazerman, Charles \& Paradis, James (Eds) Textual dynamics of the professions (pp. 337-357).

Freemantle, David (1992). Incredible customer service. Maidenhead UK: McGrawHill.

Hyon, Sunny (1996). Genre-based pedagogy in North America and Australia: Implications for ESL. TESOL Quarterly.

Johns, Ann M. (1997). Text, role and context. New York: Cambridge University Press.

Martin, David (1998). One stop customer care. Hemel Hempstead UK: Prentice Hall Europe.

Miller, Carolyn R. (1984). Genre as social action. Quarterly Journal of Speech 70. 151167.

Swales, John M. (1990). Genre analysis. Cambridge: Cambridge University Press.

Swales, John M. (1993). Genre and engagement. Revue Belge de Philologie et d'histoire 71. 687-698.

Swales, John M. \& Feak, Christine B. (2000). English in today's research world: A writing guide. Ann Arbor, MI: The University of Michigan Press. 
